\title{
Recommendations for the regulation of biosimilars and their implementation in Latin America
}

\author{
Valderilio Feijó Azevedo, MD, PhD; Eduardo Mysler, MD; Alexis Aceituno Álvarez, PharmD, PhD; Juana Hughes, MSc; \\ Francisco Javier Flores-Murrieta, PhD, FCP; Eva Maria Ruiz de Castilla, MS, MAA, PhD
}

\begin{abstract}
With the emergence of biosimilars as a new class of biotherapeutic agents, the use of these products in Latin America has become a focus of attention. To aid policymakers and regulatory authorities, a group of experts on biosimilars developed a series of recommendations for the regulation of biosimilars and their implementation in the region. Although most Latin American countries have adopted, in general, the WHO (World Health Organization) recommendations, there are some of them whose regulations differ from WHO. Unfortunately, the pace at which the region moves toward reaching its potential of having safe and effective biosimilars has been slow. Countries in the region must enhance their efforts to improve pharmacovigilance to include training more regulatory staff, more public and professional awareness on the importance of reporting adverse events and better systems to capture and analyze data. Regulatory authorities should also establish a process whereby the traceability of an adverse event to a biosimilar can be determined. Products previously approved as 'intended copy' drugs should be evaluated according to regulations specific to biosimilars. It cannot be assumed that a previously approved biopharmaceutical is actually a biosimilar, regardless of current clinical experience. Latin America is no exception to the slower-than-expected pace of developing regulations on biosimilars. The panel's perspectives on the current status led to six major recommendations in order to enhance the safe use of biosimilars in the region.
\end{abstract}

Keywords: Biological products, biosimilars, biosimilarity, Latin America, reference biotherapeutic product (RBP), regulatory pathways

\section{Introduction}

With the emergence of biosimilars as a new class of biotherapeutic agent, the use of these drug products in Latin America has become a focus of attention. To aid policymakers and regulatory authorities, the Americas Health Foundation (AHF) convened a group of experts on biosimilars to discuss the major issues related to the use of these products in Latin America. AHF relied on a number of sources to identify appropriate and potential panel members. Suggestions were received from other organizations and from individuals who had been recommended by other experts. Adjunct Professor Valderilio Azevedo was the lead contact and helped recommend and recruit other panel members so as to achieve a diverse composition of workgroup members. The AHF received a non-restrictive grant from Roche, who had no role in the decision to select panel members for the workgroup. AHF was responsible for the selection of the topic and subsequent subtopics in conjunction with the lead panel member. AHF was responsible for all logistics and expenses, including travel, hotel, and honorariums.

The facilitator for the workgroup discussion was Dr Richard Kahn, the former Chief Scientific and Medical Officer for the American Diabetes Association, who has moderated a number of consensus conferences for AHF in the past. The meeting was held over a two and a half day period of intensive and concentrated time, including 10-12 hour days. Each panel member was responsible for preparing a draft paper on his or her respectively assigned subtopic. These papers became the basis for the subsequent discussions and the final recommendations. In compiling the individual papers into a cohesive manuscript, every sentence was read, reviewed, discussed and agreed upon by the entire workgroup. Questions, comments, suggestions and disagreements were all aired openly and fully until consensus was reached.
The result of this discussion was the production of this manuscript. In this manuscript, we review the critical points in the development of regulations for the approval of biosimilars in Latin America and outline recommendations for the best implementation of regulations throughout the region.

The name biopharmaceuticals has been coined for medicinal products that contain biotechnology- or biology-derived substances (mainly proteins and polysaccharides) as their active components. There are many examples of this class of product, including human erythropoietin, insulin, growth hormone, cytokines and a number of monoclonal antibodies [1, 2].

Biotechnology processes such as recombinant DNA, controlled gene and antibody expression are the most common methods to manufacture biopharmaceuticals [3]. The manufacturing process of biopharmaceuticals plays a key role because the process itself is critical to the nature of the final product. Small differences in the design and execution of a manufacturing process can have a large influence on the clinical profile of the final product. In fact, due to the complexities associated with the manufacturing process, most biopharmaceutical manufacturers obtain a patent for the production process and not necessarily for the biotherapeutic product itself $[4,5]$.

Biosimilars are medicines similar to biopharmaceuticals that have already been approved. In other words, a biosimilar is a version of a previously approved biological medicine termed the reference product. Several names are given to biosimilars in different parts of the world, such as biocomparables, biological products, 'follow-on biologics', follow-on protein products, or subsequent entry biologicals [1, 6-8].

Biosimilars are not the same as generic versions of chemical synthesis-derived drugs. This is because the complexity of the 
manufacturing process, the heterogeneity of the final product, the active component itself, and other factors may not be identical to the reference product [9]. Biosimilars are expected to reduce drug expenditure, assuming that they achieve the same clinical results as those of the reference product $[4,10]$.

\section{Steps to approval of biosimilars}

In general, a manufacturer of biosimilars must establish that its product is similar enough to a reference product to serve as an alternative to it. Comparative quality, efficacy and safety studies are all required and must be performed in a step-wise manner to demonstrate biosimilarity.

Considering the complexity of biotherapeutic products and the limitations imposed by analytical techniques to determine whether they are indeed identical to the reference product, the approval of biosimilars must rely on demonstrating comparable clinical safety and efficacy $[4,11,12]$. To evaluate comparability, the manufacturer should first perform complete physico-chemical and biological characterization of the biosimilar on a head-to-head comparison with the reference product. Physico-chemical properties can be assessed by the primary or higher order structure using methods such as HPLC-mass spectrometry or NMR (nuclear magnetic resonance), whereas biological activity, being a measure of function, will be complementary to the physico-chemical description [13]. Cell-based assays and animal studies including pharmacodynamics and toxicity should be performed in addition to physico-chemical characterization and receptor binding. The methods used to determine the comparability between the biosimilar and its reference product must be sufficiently selective and specific to detect differences between the two. The importance of such differences can only be ascertained in preclinical and clinical studies [14].

To ensure that a biosimilar coming onto the market has the same clinical safety and efficacy as the original product, regulatory agencies need to establish well-designed pathways to achieve approval. To do this, a risk-based approach in evaluating biosimilarity has been recommended [15]. Pharmacokinetic and pharmacodynamic clinical studies are mandatory and should be done as an independent phase I study or as the initial part of a phase III trial [2]. These studies can help identify differences to the reference product, if they are present.

The route of administration and dosage of a biosimilar must be the same as the reference product. There should be similar efficacy between the biosimilar and the reference product as demonstrated in sufficiently powered, randomized, blinded controlled clinical trials. Hard clinical endpoints are essential. Any major deviation from this design should be justified. Equivalence trials (those that require a superior and an inferior comparative limit) are the preferable option for data comparison. A non-inferiority design may be used in certain circumstances, again when justified [16].

The equivalence/non-inferiority margin should be pre-specified and justified to the regulatory authorities on the basis of clinical relevance. Differences in treatment effects must also be acceptable to the medical community and not have any negative impact in patient care [17]. The indication for use of a biosimilar should reflect the results of the clinical trial showing efficacy and safety. Other indications can be extrapolated according to current guidelines (World Health Organization [WHO]) but whether a biosimilar is appropriate for related diseases, e.g. between various inflammatory diseases, is a complex issue $[18,19]$. If a biosimilar achieves an indication for one disease, it cannot automatically be assumed that the product is safe and effective for other indications simply because that is what exists for the reference product. Therefore, scientific evidence for such extrapolation should be assessed.

Another significant issue when designing a clinical trial for biosimilars is which population to choose. For example, not every patient with lymphoma will have the same response to a specific therapy; not all patients with rheumatoid arthritis will have the same response to medications that have the same indication. Patients who are methotrexate resistant do not have the same response to a biological that methotrexate naive patients have [20-22]. When deciding which population to study, the developers of a biosimilar should consider the most sensitive population that would best replicate the original results of the reference product. The intention of the clinical study is not to show the safety and efficacy of the biosimilar per se, as that has already been proven for the reference drug, but to ensure that the biosimilar has similar safety and efficacy.

Since biological agents are often immunogenic, differences between a biosimilar and its reference product may occur. That is why the immunogenicity of a biosimilar is essential to ascertain before ensuring its safety and efficacy [23]. The time to the appearance of an immunogenic reaction, as much as the type of reaction illicited, should be evaluated. Testing should have sufficient sensitivity and must have been previously validated. To determine the immunogenicity of a biosimilar, one-year follow-up pre-licensing data is normally recommended. A shorter follow-up period, e.g. six months, might be justified based on the immunogenic profile of the reference product [24].

Clinical trials rarely have the capacity to identify infrequent or unusual adverse events, so post-marketing surveillance is critical to assure drug safety [2, 15, 24-26]. In order to determine whether adverse effects are associated with a biosimilar or its reference product after approval and widespread use, some means to differentiate between the two drugs should be employed, e.g. traceability. In particular, a physician may in practice substitute the biosimilar for the reference product or, if automatic substitution is allowed, a pharmacist may switch from one drug to the other (biosimilar to original drug or vice versa) without informing or having the consent of the treating physician. In either case, it is important to be able to ascribe the cause of an adverse event to one or the other drug.

\section{Current regulations for biosimilars in Latin America}

In order to understand the regulatory framework in Latin America, it is necessary to know the historical background and worldwide situation. In the early 1980s, the introduction of biopharmaceuticals dramatically changed the treatment of some diseases. Soon after, three Latin American countries - Argentina, Cuba and Mexico - started the production of biopharmaceuticals. At that time, most Latin American countries did not have patent law, which prompted industry to make drugs 
that were copies of the reference drug. Around the year 2000, when countries belonging to the International Conference on Harmonisation of Technical Requirements for Registration of Pharmaceuticals for Human Use (including Europe, Japan and the US) began discussing how to approve 'follow-on biologics' because patents were close to expiration, Latin America had about 100 products in the market that were intended copies of reference products and registered as generics.

Under these conditions, the first regulation needed was to define the pathway for a biopharmaceutical to be approved, separate from a generic drug. Brazil and Venezuela were the first countries in Latin America to distinguish between the approval process for generics and that for biopharmaceuticals [25]. It was not until 2010 that other countries in Latin America made this distinction and even today there are countries in the region still operating under the original guidelines. For countries in the region that have regulations for the approval of biosimilars, the WHO guidelines [2] have been adopted. Although countries have adopted these regulations in general terms, there are many countries whose regulations differ from WHO.

A significant issue in Latin America is how to re-evaluate products that were previously approved but no longer fit the current criteria for a biosimilar. As mentioned above, intended copies of biologicals have been used in Latin American countries for many years and in general there were no criteria for the establishment of similarity between these products and their reference products. In 2002, Brazil began requiring more robust clinical studies in order for a product to be renewed as a biological product. Today, no country in Latin America requires a previously approved intended copy of biological drug to meet all the requirements now in effect to be considered a biosimilar as proposed by the WHO guidelines.

Two other important challenges remain. One is to improve the active pharmacovigilance system for biosimilars in a region where few adverse effects from any drugs are reported. The other challenge is that despite having comprehensive regulations for the approval of biosimilars, the region needs to develop the necessary infrastructure to evaluate the analytical and clinical information required for approval.

\section{Future of biosimilars in Latin America}

Because biologicals consume a substantial proportion of national healthcare budgets, the financial pressure to adopt biosimilars in each country is high, although each country varies in its propensity to increase access to biosimilars. The intent to promote the local manufacture of biosimilars should not distort the goal of assuring the safety and efficacy of these drugs.

In Mexico, until recently, criteria for the approval of an intended copy of biological drug was the same as for generics, meaning that preclinical and clinical data were not required. That is why in 2011 there were 23 intended copy biological drugs registered in Mexico as generics and more than 100 million doses of treatments using these drugs have been sold from 1993 to 2012. Unfortunately, due to the lack of pharmacovigilance, it has not been possible to establish the risk of using these inadequately evaluated drugs [27]. However, according to new criteria approved in Mexico in 2011, previously licensed drugs must be renewed every five years, and therefore these intended copy biological drugs will have to demonstrate true biosimilarity with physico-chemical, preclinical and clinical studies as well as pharmacovigilance, including detection of immunogenicity. At this time, Mexico has not approved a biosimilar but these intended copy biological drugs have to demonstrate true biosimilarity with physico-chemical, preclinical and clinical studies as well as pharmacovigilance, including detection of immunogenicity. However, several products are currently under evaluation at various steps of the process, and it is expected that at least one of them will be approved this year.

In Brazil, two pathways for the approval of biosimilars have emerged: a 'comparability' pathway and an 'individual development' pathway. The comparative pathway is almost identical to the WHO guidelines on evaluation of Similar Biotherapeutic Products (SBP) [2]. In the 'individual development' pathway, quality issues and clinical study requirements are reduced relative to the comparative pathway, but an extrapolation of indications, one important and controversial point regarding biosimilars, is not permitted. The comparability pathway is more rigorous and requires comparative phase I and phase III trials to the reference biotherapeutic product (RBP) and will allow extrapolation into other indications $[28,29]$. Copy products that are licensed using the comparability pathway are considered biosimilars. With government support and local production capabilities, the future commercial outlook of biosimilars in Brazil seems very promising. Under the new product development partnerships (PDPs) framework, local companies have made partnerships with international companies with expertise in producing both new biological products and biological products, see 'Glossary of Terms' below. The resulting products have a shorter timeline to approval and they also have a five-year exclusivity to sell their product to the Brazilian Government.

\section{Glossary of terms \\ Argentina \\ - Biopharmaceuticals $=$ new biological products or new originator product \\ - Biological products $=$ intended copy (biological) drugs}

Brazil

- New biological products = new originator product

- Biological products $=$ copies of new biological products

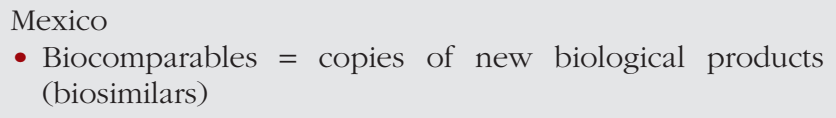

In contrast to most other countries in the region, Argentina is a major manufacturer of biopharmaceuticals - new biological products or biological products - not simply a distributor. Argentina has a well-established regulatory pathway for biosimilars [30], yet none have been marketed to date. Other countries in Latin America, such as Ecuador, Panama, Paraguay and Peru, have regulations for the approval of biosimilars. And others, such as Chile, Colombia, Uruguay and Venezuela have published draft proposals. However, implementation of the regulations has proven challenging. 
The need for well-defined pathways and regulations for the review, approval and pharmacovigilance of biosimilars, as well as greater transparency into the actions of governments, is still necessary in the region. However, a common issue with guidelines in Latin America is that regulatory authorities across countries require different levels of evidence for the approval of biosimilars.

Unfortunately, the pace at which the region moves toward reaching its potential of having safe and effective biosimilars has been slow. Of course, Latin America is no exception to the slower-than-expected pace worldwide. The introduction and uptake of biosimilars has not been optimal even in well-regulated markets such as in the European Union, while in the US, the 'follow-on biologic' regulatory pathway suggested by the US Food and Drug Administration (FDA) remains unclear [31]. It is noteworthy that not one biosimilar has been approved in the US using the US regulatory approval process. Follow-on type products have been approved, but using the stand-alone approach.

Given this backdrop, the path to harmonizing biosimilar regulations in Latin America has proven difficult. The main mechanism for such a path is the Pan American Network for Drug Regulatory Harmonization (PANDRH), which is chaired by the Pan American Health Organization (PAHO), but is essentially a multi-sectoral advisory body with no direct authority. Harmonizing biologicals/biosimilars regulations is the objective of the PANDRH's Biotechnological Products Working Group (WG BIO), which was established in 2010 and recommended that the region follows WHO guidelines [32].

At PANDRH's Seventh Conference in 2013, results of a survey conducted by PAHO of at least two countries in each subregion of Latin America demonstrated that more than half had not incorporated WHO guidelines at all, while 39 per cent used only parts of the document [33]. At the same PANDRH meeting, WHO presented results of a survey of 15 drug regulatory agencies in Latin America demonstrating substantial differences in the approach to clinical considerations in the regulation of biotherapeutic products [34]. Thus, although regulatory convergence via the PANDRH process is recognized as a priority, harmonization could still be a long way off.

As this process unfolds, it is incumbent upon Latin America's governments, non-governmental agencies, and leading health agencies to take a more active role both in developing stronger national regulations as well as the harmonization of regulations across the region.

Latin American governments also need more comprehensive and specific regulations related to biosimilars. Bare-minimum alignment with international consensus is far from a guarantee of public health safety. Rules for biosimilars that are too open for interpretation may encourage inferior imports or inferior locally manufactured products, and do so at the risk of product safety, quality and efficacy.

Governments in the region will also need to invest more heavily in their respective drug regulatory agencies. Regulations that are impossible to implement for lack of resources, e.g. staff, are of little benefit. The appropriate regulation of biosimilars requires proactive, well-resourced agencies both at the front end of product appraisal and for post-marketing surveillance and pharmacovigilance [35]. Intended copies of biologicals (versus true biosimilars) continue to proliferate in the region. Governments should consider unacceptable the continued approval of intended copies instead of biosimilars, given that the risks of these products are undetermined.

The introduction and use of biosimilars in Latin America has tremendous potential for governments, physicians, and patients. Although some progress has been made with regulations, countries of the region as a whole remain under-prepared. NonGovernmental Organizations (NGOs) have an important role in keeping governments accountable for protecting public health and patient well-being. Latin American NGOs should play a larger role in advocating for biosimilar development, approval, and post-approval surveillance. They should also be encouraged to work across borders to build a unified regional patient perspective and to demand greater levels of coordination among governments in the region.

Given the major role of PAHO, along with the South American Health Council of the Union of South American Nations (UNASUR) and the Institute for South American Institute of Government in Health (ISAGS) in health affairs within the region [36], we recommend that each of these organizations do more to encourage the development of biosimilar regulations based on WHO guidelines. The same can be said for the Council of Health Ministers of Central America (COMISCA), which is the main inter-governmental health integration mechanism for that subregion and the Dominican Republic [37].

The introduction and use of proven biosimilars should result in expanded access throughout the Americas to this important class of therapies. Proven biosimilars are likely to be cheaper than original biologicals making them more affordable for public sector health systems. Greater availability, in turn, should translate into increased use by physicians, with parallel efforts to improve the health system infrastructure to accommodate such use. Increasing utilization rates will help drive market competition to the further benefit of governments (lower prices), physicians (more tools to combat disease), and patients (increased access to modern therapies)

\section{Final recommendations}

We propose a number of recommendations that should significantly enhance the appropriate review, approval and safe use of biosimilars. We greatly encourage all interested parties to consider implementing the following:

1. Enhanced training of regulatory authorities on how to evaluate biosimilars. Having staff with appropriate skills and expertise and the sharing of knowledge between health authorities in the region are important.

2. Establishment of a region-wide working group, under the auspices of $\mathrm{PAHO}$, comprising representatives from regulatory authorities from various Latin American countries with expertise in biosimilars, whose purpose is to share their regulatory experience and plans related to biosimilars.

3. Each country in Latin America should establish its own working group, comprising people with interest in biosimilars, to assist regulatory authorities in their efforts to develop and introduce biosimilars into their respective countries. 
4. A dedicated portion on the PRAIS website (PAHO's Regional Platform on Access and Innovation for Health Technologies [38]) to promote discussion on biosimilars, such topics as ongoing studies, recent approvals, and problems and issues of concern would be the focus; and to foster transparency.

5. Countries in Latin America must enhance their efforts to improve pharmacovigilance to include training more regulatory staff dedicated to this endeavour, more public and professional awareness on the importance of reporting adverse events, and better systems to capture and analyse data. Regulatory authorities should also establish a process whereby the traceability of an adverse event to a biosimilar or its RBP can be determined.

6. Products previously approved as 'intended copy' biological drugs should be evaluated according to regulations specific to biosimilars. It cannot be assumed that a previously approved biopharmaceutical is actually a biosimilar, regardless of current clinical experience. Reassessment is essential and the pharmaceutical industry should perform the necessary studies in a timely fashion.

\section{Panel members}

Adjunct Professor Valderilio Feijó Azevedo, MD, PhD

Federal University of Paraná

224 Rua Alvaro Alvin, Casa 18 Seminário, Curitiba-Paraná PR 80740-260, Brasil

Eduardo Mysler, MD

Organización Médica de Investigación (OMI)

Uruguay 725 PB, CABA, CP 1015, Argentina

Alexis Aceituno Álvarez, PharmD, PhD

Facultad de Farmacia, Universidad de Valparaíso, Chile

Instituto de Salud Pública de Chile (ISPC)

1000 Av Marathon, Nuñoa, Santiago, Chile

Casilla 48 Correo Central 21, Código Postal 7780050, Chile

Juana Hughes, MSc

Consultant on Pharmaceutical Affairs, Specialization on Biotech Products

1721 Lido, Montevideo 11500, Uruguay

Francisco Javier Flores-Murrieta, PhD, FCP

Sección de Estudios de Posgrado e Investigación del Instituto Politécnico Nacional and Unidad de Investigación en Farmacología, Instituto Nacional de Enfermedades Respiratorias Ismael Cosío Villegas - Mexico

4502 Calzada de Tlalpan, Colonia Sección XVI, 14080 México, Distrito Federal

Eva Maria Ruiz de Castilla, MS, MAA, PhD

International Alliance of Patients' Organizations

363 Calle Conde de la Monclova, Dpto 1102, Torre Libertadores San Isidro Lima, 27 Perú

Competing interests: Ms Juana Hughes is a paid advisor for Merck Serono and was paid by AbbVie for giving lectures. Dr Alexis Aceituno Álvarez - no conflicts of interest. Dr Eva Maria Ruiz de Castilla - no conflicts of interest. Dr Francisco Javier FloresMurrieta - no conflicts of interest. Adjunct Professor Valderilio
Feijó Azevedo - a member of the Global Advisory Board on Biosimilars of AbbVie, Merck Serono and Pfizer; and has spoken for, and been involved with clinical trials for AbbVie, AstraZeneca, Bristol-Myers Squibb, GSK, Janssen, Novo Nordisk, Pfizer, Sanofi, UCB. Dr Eduardo Mysler - speaker, advisor and investigator for AbbVie, AstraZeneca, Biogen Indec, BristolMyers Squibb, Janssen, mAbxience, Merck, Novartis, Novo Nordisk, Pfizer, Roche, Samsung, Sanofi and UCB.

Provenance and peer review: Not commissioned; externally peer reviewed.

\section{Co-authors}

Eduardo Mysler, MD

Alexis Aceituno Álvarez, PharmD, PhD

Juana Hughes, MSc

Francisco Javier Flores-Murrieta, PhD, FCP

Eva Maria Ruiz de Castilla, MS, MAA, PhD

\section{References}

1. Kresse GB. Biosimilars-science, status, and strategic perspective. Eur J Pharm Biopharm. 2009;72(3):479-86.

2. World Health Organization. Expert Committee on Biological Standardization. Guidelines on evaluation of similar biotherapeutic products (SBPs). Geneva, 19-23 October, 2009 [homepage on the Internet]. 2010 Apr 6 [cited 2014 May 27]. Available from: http://www.who.int/biologicals/areas/ biological_therapeutics/BIOTHERAPEUTICS_FOR_WEB_22APRIL2010.pdf

3. Misra A. Are biosimilars really generics? Expert Opin Biol Ther. 2010;10(4): 489-94.

4. Roger SD. Biosmilars: current status and future directions. Expert Opin Biol Ther. 2010;10(7):1011-8.

5. Wenzel RG. Current legal, regulatory, and scientific implications of biosimilars. Introduction. Am J Health Syst Pharm. 2008;65(14 Suppl 6):S1. doi:10.2146/ ajhp080209

6. Strand V, Cronstein B. Biosimilars: how similar? Intern Med J. 2014 Mar;44(3): 218-23. doi:10.1111/imj.12292

7. Minghetti P, Rocco P, Del Vecchio L, Locatelli F. Biosimilars and regulatory authorities. Nephrol Clin Pract. 2011;117(1):c1-7.

8. Thorpe R, Wadhwa M. Terminology for biosimilars-a confusing minefield. Generics and Biosimilars Initiative Journal (GaBI Journal). 2012;1(3-4):132-4. doi:10.5639/gabij.2012.0103-4.023

9. Declerck PJ, Darendeliler F, Góth M, Kolouskova S, Micle I, Noordam C, et al. Biosimilars: controversies as illustrated by rhGH. Curr Med Res Opin. 2010;26(5):1219-29.

10. Haustein R, de Millas C, Höer A, Häussler B. Saving money in the European healthcare systems with biosimilars. Generics and Biosimilars Initiative Journal (GaBI Journal). 2012;1(3-4).120-6. doi:10.5639/gabij.2012. 0103-4.036

11. Thorpe R. Biosimilar monoclonal antibodies approved for use in the EU. Generics and Biosimilars Initiative Journal (GaBI Journal). 2014;3(1):9. doi: 10.5639/gabij.2014.0301.004

12. Scheneider C, Borg J, Ehmann F, Ekman N, Hienonen E, Ho K, et al. In support of the European Union biosmilar framework. Nat Biotech. 2012;30(8): 745-8.

13. Minghetti P, Rocco P, Cilurzo F, Del Vecchio L, Locatelli F. The regulatory framework of biosimilars in the European Union. 2012. Drug Discovery Today. 2012;17(1-2):63-70.

14. Simoens S, Verbeken G, Huys I. Biosimilars and market access: a question of comparability and costs? Target Oncol. 2012;7(4):227-31. 
15. Shapiro M. Quality Considerations for biosimilars. Federal Drug Administration. Division of Monoclonal Antibodies/OBP/OPS. Advisory Committee for Pharmaceutical Science and Clinical Pharmacology. 8 Aug 2012. Presentation [homepage on the Internet]. 2012 Aug 16 [cited 2014 May 17]. Available from: http://www.fda.gov/downloads/AdvisoryCommittees/CommitteesMeetingMaterials/Drugs/AdvisoryCommitteeforPharmaceuticalScienceandClinicalPharmacology/UCM315764.pdf

16. European Medical Agency. Committee for Medicinal Products for Human Use (CHMP). Guideline on the choice of the non-inferiority margin. London, 27 July 2005. Doc. Ref. EMEA/CPMP/EWP/2158/99 [homepage on the Internet]. 2012 Aug 16 [cited 2014 May 17]. Available from: http://www.ema. europa.eu/docs/en_GB/document_library/Scientific_guideline/2009/09/ WC500003636.pdf

17. Joung J, Robertson JS, Griffiths E, Knezevic I. WHO informal consultation on regulatory evaluation of therapeutic biological medicinal products held at WHO Headquarters, Geneva, 19-20 April 2007. Biologicals. 2008;36(4):269-76.

18. Sandborn WJ, Hanauer SB, Katz S, Safdi M, Wolf DG, Baerg RD, et al. Etanercept for active Crohn's disease: a randomized, double-blind, placebocontrolled trial. Gastroenterology. 2001 Nov;121(5):1088-94.

19. Colombel JF, Sandborn WJ, Rutgeerts P, Enns R, Hanauer SB, Panaccione R, et al. Adalimumab for maintenance of clinical response and remission in patients with Crohn's disease: the CHARM trial. Gastroenterology. 2007 Jan;132(1):52-65.

20. Keystone E, Genovese MC, Klareskog L, Hsia EC, Hall S, Miranda PC, et al. Golimumab in patients with active rheumatoid arthritis despite methotrexate therapy: 52-week results of the GO-FORWARD study. Ann Rheum Dis. 2010 Jun;69(6):1129-35.

21. Smolen JS, Kay J, Doyle MK, Landewé R, Matteson EL, Wollenhaupt J, et al; GO-AFTER study investigators. Golimumab in patients with active rheumatoid arthritis after treatment with tumour necrosis factor alpha inhibitors (GOAFTER study): a multicentre, randomised, double-blind, placebo-controlled, phase III trial. Lancet. 2009 Jul 18;374(9685):210-21.

22. Emery P, Fleischmann RM, Moreland LW, Hsia EC, Strusberg I, Durez P, et al. Golimumab, a human anti-tumor necrosis factor alpha monoclonal antibody, injected subcutaneously every four weeks in methotrexate-naive patients with active rheumatoid arthritis: twenty-four-week results of a phase III, multicenter, randomized, double-blind, placebo-controlled study of golimumab before methotrexate as first-line therapy for early-onset rheumatoid arthritis. Arthritis Rheum. 2009 Aug;60(8):2272-83.

23. Dranitsaris G, Amir E, Dorward K. Biosimilars of biological drug therapies: regulatory, clinical and commercial considerations. Drugs. 2011;71:1527-36.

24. European Medical Agency. Committee for Medicinal Products for Human Use (CHMP). Guideline on similar biological medicinal products containing biotechnology-derived proteins as active substance: non-clinical and clinical issues. London, 22 February 2006. EMEA/CHMP/BMWP/42832/2005 [homepage on the Internet]. 2006 Mar 8 [cited 2014 May 27]. Available from: http://www.ema.europa.eu/docs/en_GB/document_library/Scientific_ guideline/2009/09/WC500003920.pdf

25. World Health Organization. Marketing authorization of pharmaceutical products with special reference to multisource (generic) products: a manual for drug regulatory authorities. WHO/DMP/RGS/98.5. Pg. 105 [homepage on the Internet]. 2002 Jan 18 [cited 2014 May 27]. Available from: http://
apps.who.int/prequal/info_general/documents/WHO_DMP_RGS_98_5_R. pdf

26. Giezen TJ, Straus SMJM. Pharmacovigilance of biosimilars: challenges and possible solutions. Generics and Biosimilars Initiative Journal (GaBI Journal). 2012;1(3-4):118-9. doi:10.5639/gabij.2012.0103-4.033

27. Ibarra-Cabrera R, Mena-Pérez SC, Bondani-Guasti A, García-Arrazola R. Review on the worldwide regulatory framework for biosimilars focusing on the Mexican case as an emerging market in Latin America. Biotechnol Adv. 2013 Dec;31(8):1333-43.

28. Kirchlechner T. Current regulations of biosimilars in the Latin American region. 3rd Annual Drug Information Association (DIA) Latin American Regulatory Conference; 12-15 Apr 2011; Panama City, Panama.

29. Castanheira LG, Barbano DB, Rech N. Current development in regulation of similar biotherapeutic products in Brazil. Biologicals. 2011;39(5):308-11.

30. Mysler E, Scheinberg M. Biosimilars in rheumatology: a view from Latin America. Clin Rheumatol. 2012;31(9):1279-80.

31. Dalgaard K, Evers M, Santos da Silva J. Biosimilars seven years on: where are we and what's next? Insights into Pharmaceuticals and Medical Products. February 2013 [homepage on the Internet]. 2013 Feb 12 [cited 2014 May 27]. Available from: http://www.mckinsey.com/ /media/mckinsey/dotcom/client_service/ Pharma\%20and\%20Medical\%20Products/PMP\%20NEW/PDFs/Biosimilars\%20 Seven\%20years\%20on_White\%20Paper.ashx

32. Pan American Health Organization. Red PARF Documento Técnico No. 7: Recomendaciones para la Evaluación de Productos Bioterapéuticos Similares (PBS). (Español y portugués). June 2011 [homepage on the Internet]. 2011 Jun 29 [cited 2014 May 27]. Available from: http://www.paho.org/hq./index. php?option=com_docman\&task=doc_download $\&$ gid $=13592 \&$ Itemid $=\&$ lang $=$ en

33. Saidon P. Level of adoption and implementation of technical document $N^{\circ} 7$. VII Conference of the Pan American Network for Drug Regulatory Harmonization; 5-7 September 2013; Ottawa, Canada. [homepage on the Internet]. [cited 2014 May 27]. Available from: http://www.paho.org/hq/ index.php?option=com_docman\&task=doc_download $\&$ gid $=22906 \&$ Itemid $=2$ $70 \&$ lang $=$ en

34. Knezevic I. WHO Survey on Biotherapeutic Products (focus on clinical issues). VII Conference of the Pan American Network for Drug Regulatory Harmonization. 5-7 September 2013; Ottawa, Canada [homepage on the Internet]. [cited 2014 May 27]. Available from: http://www.paho.org/hq/index.php?option= com_docman\&task=doc_download\&gid=22904\&Itemid=270\&lang=en

35. IMS Institute for Health Informatics. The global use of medicines: outlook through 2017. November 2013 [homepage on the Internet]. 2013 Dec 12 [cited 2014 May 27]. Available from: http://www.imshealth.com/deployedfiles/imshealth/ Global/Content/Corporate/IMS\%20Health\%20Institute/Reports/Global_Use_of_ Meds_Outlook_2017/IIHI_Global_Use_of_Meds_Report_2013.pdf

36. ISAGS. Health Council [homepage on the Internet]. [cited 2014 May 27]. Available from: http://www.isags-unasul.org/ interna.asp?lang=2\&idarea $=37$

37. SICA. COMISCA en breve [homepage on the Internet]. [cited 2014 May 27]. Available from: http://www.sica.int/comisca/comisca_enbreve.aspx

38. Pan American Health Organization. Regional Platform on Access and Innovation for Health Technologies [homepage on the Internet]. [cited 2014 May 27. Available from: http://prais.paho.org/rscpaho

DOI: 10.5639/gabij.2014.0303.032

Copyright @ 2014 Pro Pharma Communications International 